\title{
Amplification of obliquity forcing through mean annual and seasonal atmospheric feedbacks
}

\author{
S.-Y. Lee and C. J. Poulsen \\ Department of Geological Sciences, University of Michigan, Ann Arbor, MI, USA \\ Received: 17 March 2008 - Published in Clim. Past Discuss.: 25 April 2008 \\ Revised: 18 July 2008 - Accepted: 8 August 2008 - Published: 15 October 2008
}

\begin{abstract}
Pleistocene benthic $\delta^{18} \mathrm{O}$ records exhibit strong spectral power at $\sim 41 \mathrm{kyr}$, indicating that global ice volume has been modulated by Earth's axial tilt. This feature, and weak spectral power in the precessional band, has been attributed to the influence of obliquity on mean annual and seasonal insolation gradients at high latitudes. In this study, we use a coupled ocean-atmosphere general circulation model to quantify changes in continental snowfall associated with mean annual and seasonal insolation forcing due to a change in obliquity. Our model results indicate that insolation changes associated with a decrease in obliquity amplify continental snowfall in three ways: (1) Local reductions in air temperature enhance precipitation as snowfall. (2) An intensification of the winter meridional insolation gradient strengthens zonal circulation (e.g. the Aleutian low), promoting greater vapor transport from ocean to land and snow precipitation. (3) An increase in the summer meridional insolation gradient enhances summer eddy activity, increasing vapor transport to high-latitude regions. In our experiments, a decrease in obliquity leads to an annual snowfall increase of $25.0 \mathrm{~cm}$; just over one-half of this response $(14.1 \mathrm{~cm})$ is attributed to seasonal changes in insolation. Our results indicate that the role of insolation gradients is important in amplifying the relatively weak insolation forcing due to a change in obliquity. Nonetheless, the total snowfall response to obliquity is similar to that due to a shift in Earth's precession, suggesting that obliquity forcing alone can not account for the spectral characteristics of the ice-volume record.
\end{abstract}

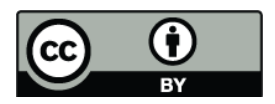

Correspondence to: S.-Y. Lee (shihyu@umich.edu)

\section{Introduction}

It has long been known that the Quaternary global icevolume record, archived in benthic $\delta^{18} \mathrm{O}$, varies at orbital frequencies (Hays et al., 1976; Imbrie, 1980, 1985, 1993). One of the most puzzling features of this record is the prominence of variability at the obliquity period (Raymo and Nisancioglu, 2003; Lisiecki and Raymo, 2005; Cortijo et al., 1999; Vimeux et al., 2001). Traditionally, orbital cycles in global ice volume have been linked to summer insolation at $65^{\circ} \mathrm{N}$ (Milankovitch, 1948; Berger et al., 1993). However, high-latitude summer insolation is influenced most strongly by Earth's precession with a period of $\sim 23 \mathrm{kyr}$. It is perplexing then that spectral power in benthic $\delta^{18} \mathrm{O}$ is greater in the obliquity band than the precessional band.

To explain this paradox, two types of hypotheses have been proposed, (i) those that are generally consistent with Milankovitch's original hypothesis and (ii) those that call upon internal climate processes to amplify orbital, and specifically obliquity, forcing. In the first category, Huybers (2006) suggests that obliquity primarily controlled icevolume changes through the integrated summer energy, which is a function of both insolation intensity and duration. Though precession has a large influence on high-latitude summer insolation intensity, this influence is counteracted by a change in the duration of summer due to variations in Earth's angular speed (in an elliptical orbit) as it revolves around the Sun. Raymo et al. (2006) proposes that the change in benthic $\delta^{18} \mathrm{O}$ due to the increase in the $\mathrm{NH}$ ice volume was offset by the melting of the West Antarctic Ice Sheet due to out-of-phase precessional insolation forcing between the two hemispheres. The strong $41 \mathrm{kyr}$ ice-volume signal was also attributed to the fact that obliquity has nearly twice the period of precession, and therefore twice the time to accumulate snow/ice (Ruddiman, 2003). In the second category, it has been proposed that climate feedbacks, mainly associated

Published by Copernicus Publications on behalf of the European Geosciences Union. 
with meridional heat and vapor transports (Khodri et al., 2001; Crucifix and Loutre, 2002; Raymo and Nisancioglu, 2003; Loutre et al., 2004; Vettoretti and Peltier, 2004; Kukla and Gavin, 2004; Risebrobakken et al., 2006) and $\mathrm{CO}_{2}$-ice volume interaction (Ruddiman, 2006), may have modulated the insolation forcing, enhancing the ice volume response to orbital forcing.

The focus on climate feedbacks on orbital forcing arises from recognition that obliquity and precession affect Earth's insolation in different ways. In contrast to precession, obliquity alters the mean-annual equator-to-pole insolation gradient. A reduction in axial tilt from the Plio-Pleistocene maximum $\left(24.5^{\circ}\right)$ to minimum $\left(22.2^{\circ}\right)$ reduces annual insolation by up to $\sim 16 \mathrm{~W} \mathrm{~m}^{-2}(\sim 8 \%)$ at high latitudes and increases it by $\sim 3 \mathrm{~W} \mathrm{~m}^{-2}(<0.5 \%)$ at the equator (calculated from Berger and Loutre, 1991). Loutre et al. (2004) show that mean-annual insolation has significant spectral power at the obliquity band and hypothesize that paleo-climate records of sea-surface temperature and global ice volume can be interpreted as a response to changes in mean-annual insolation and insolation gradients.

Obliquity also has a substantial influence on seasonal insolation. A reduction in Earth's obliquity from the PlioPleistocene maximum to minimum reduces solar heating in summer and fall seasons by up to $48 \mathrm{~W} \mathrm{~m}^{-2}$ at high latitude and increases it by $7 \mathrm{~W} \mathrm{~m}^{-2}$ near the equator, enhancing the equator-to-pole insolation gradient by $55 \mathrm{~W} \mathrm{~m}^{-2}$. A number of studies have suggested that an increase in the seasonal equator-to-pole insolation gradient might have enhanced snowfall over ice sheets due to greater latent heat transport and internal climate processes (e.g. ENSO-like oscillation) (Johnson, 1991; Khodri et al., 2001; Vettoretti and Peltier, 2003, 2004; Kukla and Gavin, 2004). In support of these ideas, Raymo and Nisancioglu (2003) show that the summer equator-to-pole insolation gradient is in-phase with benthic $\delta^{18} \mathrm{O}$ during the early Pleistocene.

Although insolation gradient changes have been frequently linked to ice volume variability, this mechanism has not been explicitly tested. The goal of this study is to systematically quantify the influence of both mean annual and seasonal insolation changes resulting from Earth's obliquity on continental snowfall, and to determine the climate mechanisms that respond to these insolation variations. To do this, we have developed coupled ocean-atmosphere model experiments that represent: (1) mean annual and seasonal insolation changes due to a reduction in Earth's axial tilt; and (2) mean-annual-only insolation changes due to a reduction in Earth's axial tilt. To be clear, the insolation conditions in (2) are idealized and provide a useful sensitivity experiment, but would not have occurred anytime during Earth history. By comparing results from these two scenarios, we distinguish the climate responses to mean annual and seasonal forcings.

Our model results indicate that mean seasonal and annual insolation forcings associated with a decrease in axial tilt generate comparable changes in annual continental snowfall.
In Sect. 3, we describe the snowfall differences and explain the physical mechanisms that account for these changes. In Sect. 4, we compare the snowfall response due to changes in Earth's obliquity and precession, and discuss the implications of these results for global ice-volume variability.

\section{Experimental design}

This study was completed using the Fast Ocean Atmosphere Model (FOAM) version 1.5, a fully coupled mixedresolution ocean and atmosphere general circulation model (GCM) (Jacob, 1997). The atmospheric model is a parallelized version of the Community Climate Model 2 (CCM2) with the upgraded radiative and hydrological physics incorporated in CCM3.6 (Kiehl et al., 1996). The atmospheric component of FOAM was run at a spectral resolution of R15 $\left(4.5^{\circ} \times 7.5^{\circ}\right)$ with 18 vertical levels. The oceanic component (OM3) is a $\mathrm{z}$-coordinate ocean model with $128 \times 128$ point Mercator grid $\left(1.4^{\circ} \times 2.8^{\circ}\right), 24$ vertical levels, and an explicit free surface. FOAM was designed for long century-scale integrations and exhibits minimal ocean drift with no flux corrections (Wu et al., 2003). FOAM's simulation of modern climate shows reasonable agreement with present-day observations and NCAR CSM (Harrison et al., 2003). FOAM has been widely used to study climate change through geological time (e.g. Liu et al., 2000; Poulsen et al., 2001; Lee and Poulsen, 2006).

A change in Earth's axial tilt alters the distribution of insolation, significantly influencing both mean annual and seasonal meridional insolation gradients. A decrease in Earth's obliquity from 24.5 to $22.2^{\circ}$, for instance, increases the mean-annual equator-to-pole insolation gradient by $\sim 20 \mathrm{~W} \mathrm{~m}^{-2}$, the summer equator-to-pole insolation gradient by $\sim 55 \mathrm{~W} \mathrm{~m}^{-2}$, and only slightly increases the winter equator-to-pole insolation gradient. We have designed two sets of experiments to estimate the climate response to each of these components. The first experimental set is straightforward and includes experiments with high ( $24.5^{\circ}$; "hobl") and low (22.2 ; "lobl") axial tilt (Table 1). We have used Earth's maximum and minimum obliquities over the last five million years (Berger and Loutre, 1991). The difference between "hobl" and "lobl" experiments yields the climate response resulting from both mean annual and seasonal insolation changes (Fig. 1a), which we refer to as $\triangle$ TOTAL.

A second set of experiments was designed to estimate the climate response to just mean-annual insolation forcing caused by a change in axial tilt. This was accomplished by adding mean-annual insolation anomalies from the high and low obliquity experiments to a present-day experiment. These insolation adjustments increase the annual equator-topole insolation in one experiment ("higrad") and decrease it in the second ("lograd") (Table 1), but seasonal insolation and insolation gradients are nearly identical between experiments and unchanged from the present day. In the 
"higrad" case, the high-latitude insolation anomaly is negative. Adding this negative insolation anomaly during polar night would cause the incoming insolation to become negative, which is unreasonable and not allowed by the model. To avoid this problem, the minimum insolation was set to $0 \mathrm{~W} \mathrm{~m}^{-2}$ during polar night. This correction affects slightly the winter season (polar night) insolation and equator-to-pole gradient at $70-90^{\circ}$ (as seen in Fig. 1b), but does not have an appreciable influence on the snowfall response (which is mainly centered at $60-65^{\circ}$ ). The difference between "higrad" and "lograd" experiments yields the climate response to obliquity's mean-annual forcing, which we refer to as $\triangle$ MA.

It is important to note that mean-annual insolation in the "higrad" and "lograd" experiments are identical to those in the "hobl" and "lobl" experiments, respectively, and that only seasonal insolation differs between these experiments (Fig. 1). As a result, the mean-annual insolation difference in $\triangle$ TOTAL and $\triangle \mathrm{MA}$ are also the same. Thus, to estimate the climate response to seasonal insolation only $(\triangle \mathrm{SEA})$, we difference our two sets of experiments. In summary:

$\triangle$ TOTAL $=$ "lobl" - "hobl";

represents total insolation difference due to a reduction in axial tilt

$\Delta \mathrm{MA}=$ "higrad" - "lograd";

represents the mean-annual insolation difference due to a reduction in axial tilt

$\Delta \mathrm{SEA}=\Delta \mathrm{TOTAL}-\Delta \mathrm{MA} ;$

represents the seasonal insolation difference due to a reduction in axial tilt.

Because our ultimate objective is to explain variability in the ice-volume record, in the presentation of the results, we compare the climate response between $\triangle \mathrm{TOTAL}$ and $\triangle \mathrm{MA}$.

Other than insolation changes related to obliquity, all model boundary conditions were set to modern values including trace gas concentrations, solar luminosity, eccentricity and precession, vegetation, and geography. The experiments were each integrated for 200 years, bringing the surface ocean into quasi-equilibrium. We tested the quasiequilibrium state by comparing decadal-averaged global and high-latitude $\left(50^{\circ} \mathrm{N}-90^{\circ} \mathrm{N}\right)$ sea surface temperatures. The sea-surface temperatures respond to the imposed orbital forcing in the initial $40-110$ years. After model year 120, global and high-latitude sea-surface temperature trends are very small, 0.02 and $0.05^{\circ} \mathrm{C} /$ decade, respectively. Though the surface is in near equilibrium, the deep ocean is still equilibrating. However, because we focus our analysis on surface and tropospheric condition, the deep ocean condition should have little effect on surface temperature and continental snowfall. The model results presented here were averaged over the last 50 model years.

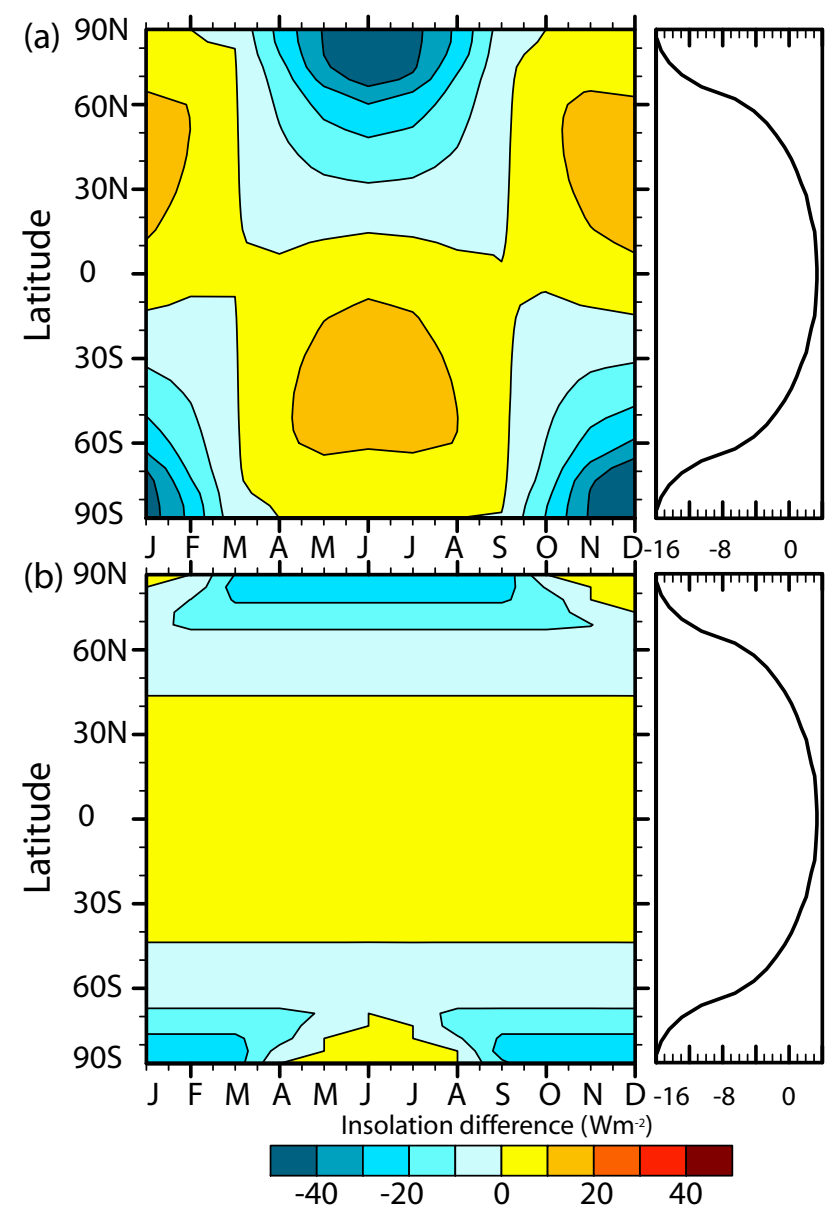

Fig. 1. Mean monthly (left column) and annual (right column) insolation difference ( $\mathrm{W} \mathrm{m}^{-2}$ ) between $\triangle$ TOTAL (a "lobl"-"hobl") and $\triangle$ MA (b "higrad"-"lograd") experiments. The insolation difference in $\triangle \mathrm{MA}$ yields the climate response to obliquity's meanannual forcing (see Sect. 2 for detailed description). Contour interval is $10 \mathrm{~W} \mathrm{~m}^{-2}$. Seasonal insolation differs between these experiments sets, but the mean-annual insolation is identical between $\triangle$ TOTAL and $\triangle \mathrm{MA}$.

\section{Result}

\subsection{Snowfall response}

To quantify the possible contribution made by mean annual and seasonal forcing to ice-sheet mass balance, we examine the high-latitude continental snowfall responses to both $\triangle$ TOTAL and $\triangle$ MA. In $\triangle$ TOTAL, zonal continental snowfall increases by $25.0 \mathrm{~cm}$ (sum of upper and lower panel of Fig. 2a). In contrast, in $\triangle M A$, annual snowfall increases by $10.9 \mathrm{~cm}$ (sum of upper and lower panel of Fig. 2b). The global seasonal snowfall response ( $\triangle$ SEA shown in Fig. $2 c$ ) is $14.1 \mathrm{~cm}$, indicating that mean annual and seasonal insolation changes contribute almost equally to the total continental snowfall response. In both $\triangle \mathrm{TOTAL}$ and $\triangle \mathrm{MA}$, the snowfall response occurs mainly during the summer half-year. In the 
Table 1. Numerical climate experiments.

\begin{tabular}{|c|c|c|c|}
\hline Experiments & Obliquity & Anomaly & Note \\
\hline "lobl" & $22.2^{\circ}$ & & $\begin{array}{l}\triangle \text { TOTAL }=\text { "lobl"-"hobl" } \\
\text { Total changes due to obliquity's mean-annual \& } \\
\text { seasonal forcing }\end{array}$ \\
\hline "hobl" & $24.5^{\circ}$ & & \\
\hline "higrad" & $23.4^{\circ}$ & $\begin{array}{l}\text { Anomaly increasing the mean-annual insolation } \\
\text { gradient so that it is the same in "lobl" }\end{array}$ & $\begin{array}{l}\Delta \mathrm{MA}=\text { "higrad"-"lograd" } \\
\text { Changes due to obliquity's mean-annual forcing } \\
\Delta \mathrm{SEA}=\Delta \text { TOTAL- } \triangle \mathrm{MA} \\
\text { Changes due to obliquity's seasonal forcing }\end{array}$ \\
\hline
\end{tabular}

"lograd" $23.4^{\circ} \quad \begin{aligned} & \text { Anomaly increasing the mean-annual insolation } \\ & \text { gradient so that it is the same in "hobl" }\end{aligned}$
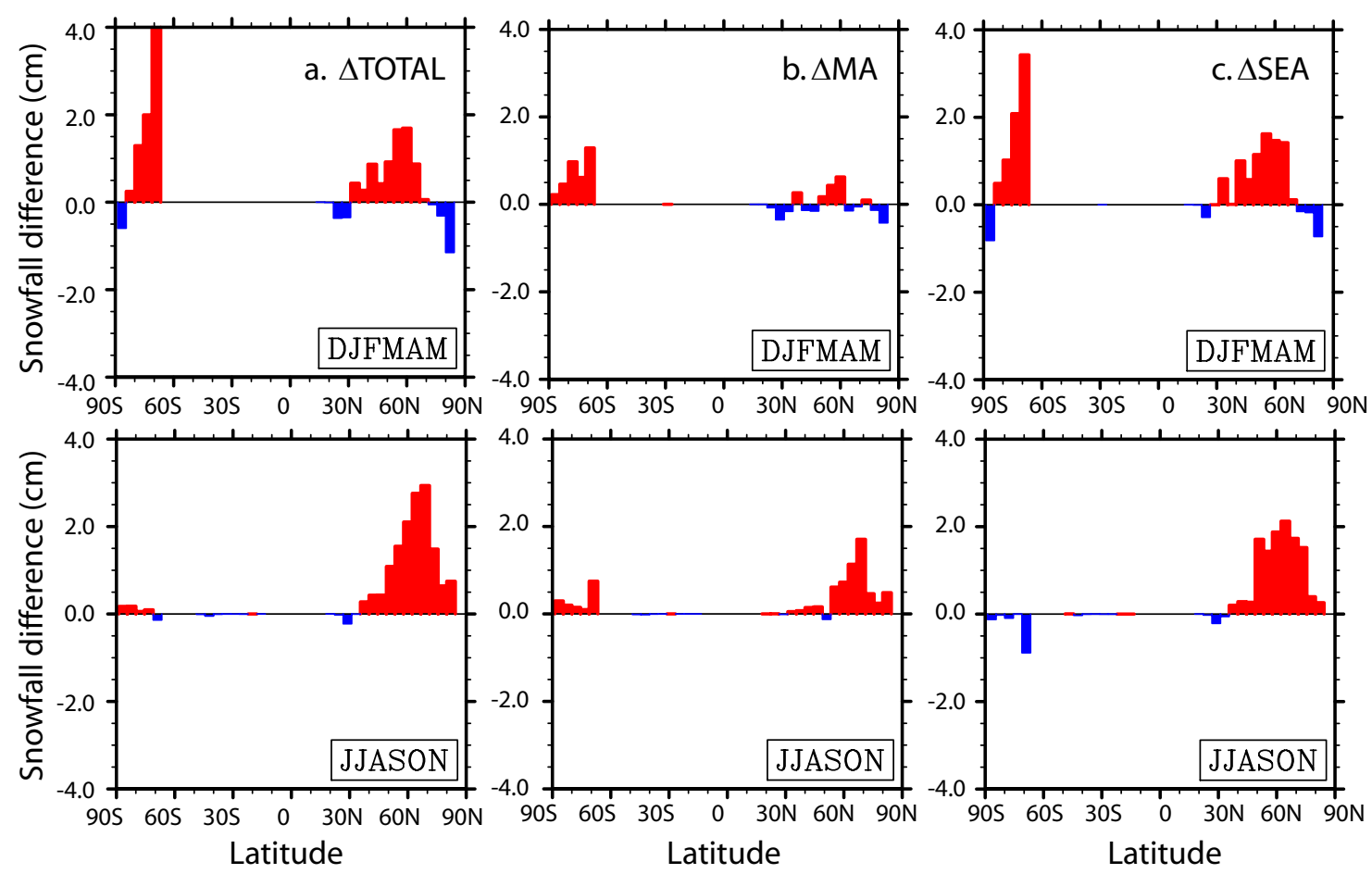

Fig. 2. Continental snowfall response to orbital forcing. Zonally-average half-year (December through May and June through November) differences in total snowfall (cm): (a) $\triangle$ TOTAL ("lobl"-"hobl"), (b) $\Delta$ MA ("higrad"-"lograd"), and (c) $\Delta$ SEA ( $\Delta$ TOTAL- $\triangle$ MA).

Northern Hemisphere, for example, a reduction in obliquity ( $\triangle$ TOTAL) enhances summer half-year snowfall by $78 \%$ and winter half-year snowfall by $22 \%$ (Fig. 2b).

Differences in snowfall are mainly due to differences in non-convective stable snowfall, which are closely related to temperature and moisture transport. Non-convective precipitation in FOAM forms when an air parcel exceeds vapor saturation, and becomes snow when the lowest level of the atmosphere and the land surface are below the freezing point of water (Kiehl et al., 1996). A decrease in obliquity alters inso- lation in two ways that might enhance the total snow formation in $\triangle$ TOTAL relative to $\triangle \mathrm{MA}$ : (1) by decreasing insolation and temperature at high latitudes; and/or (2) by enhancing the seasonal meridional insolation gradient and moisture transport. We examine each of these factors below.

\subsection{Winter snowfall response}

The winter snowfall response in $\triangle$ TOTAL accounts for onequarter of the total annual snowfall difference. Northern 
(a) surface temperature (C)

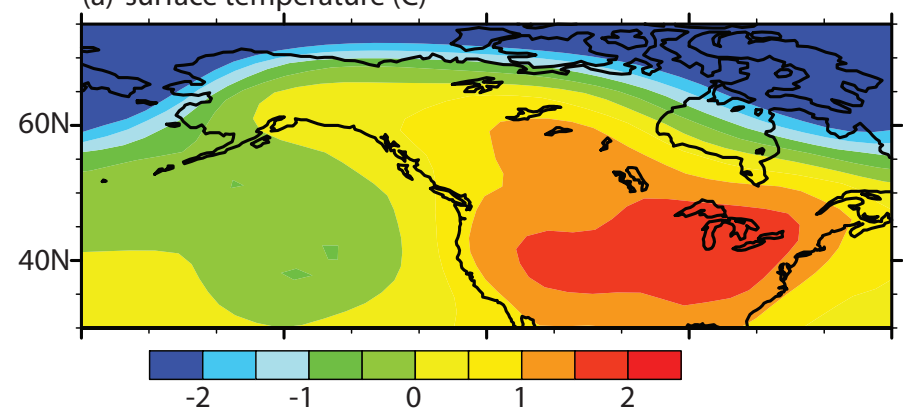

(c) $750 \mathrm{mb}$ temperature (C)

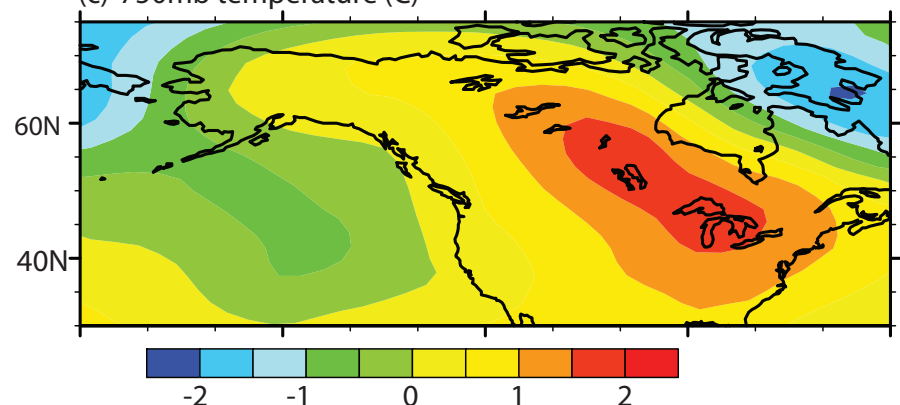

(e) relative humidity $(\%)$

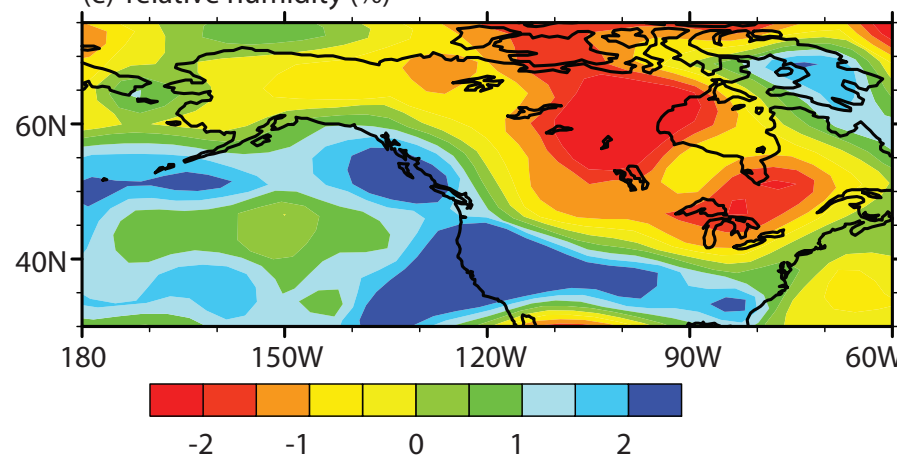

(b) surface pressure level $(\mathrm{mb})$ \& wind $\left(\mathrm{ms}^{-1}\right)$

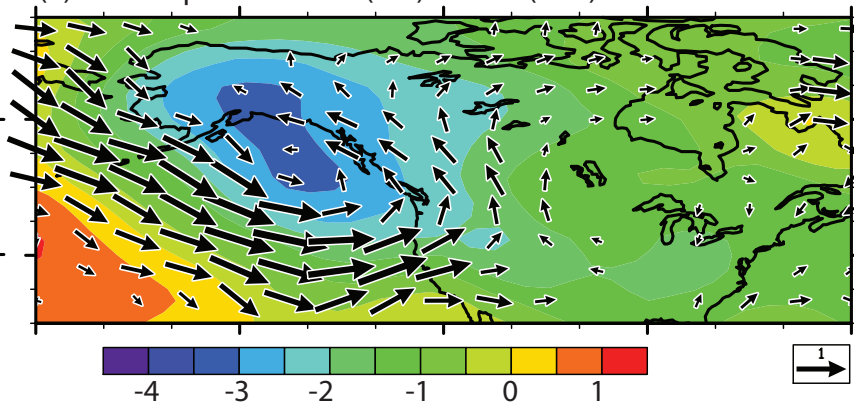

(d) latent heat flux $\left(\mathrm{Wm}^{-2}\right)$

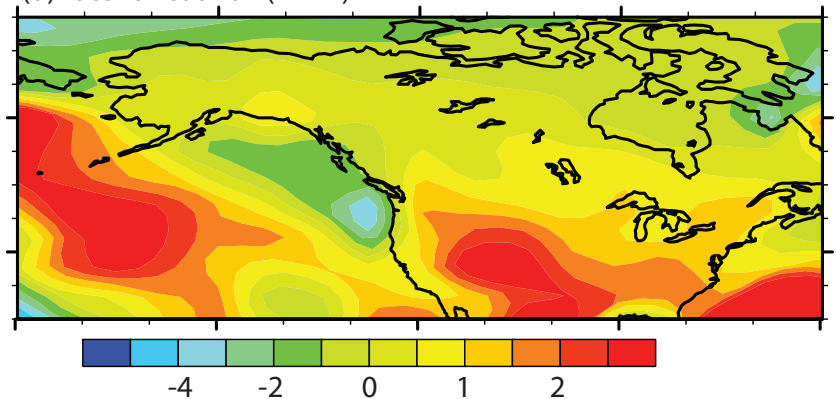

(f) continental snowfall rate $\left(\mathrm{cmmo}^{-1}\right)$

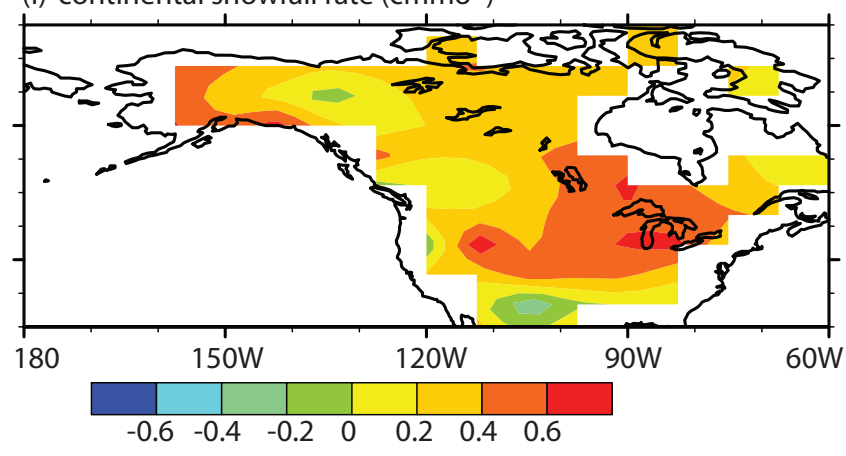

Fig. 3. Differences in January-February-March atmospheric conditions over North America due to a decrease in obliquity ( $\Delta \mathrm{TOTAL}$ ). (a) Surface-air temperature (in degree Celsius), (b) Lower tropospheric wind (vectors; averaged from surface to $750 \mathrm{mb}$ ) and surface level pressure (contour; in mb), (c) Lower tropospheric $(750 \mathrm{mb})$ air temperature (in degrees Celsius), (d) Latent heat flux (in $\mathrm{W} \mathrm{m}^{-2}$ ), (e) Relative humidity (in \%), and (f) Continental snowfall rate (in $\mathrm{cm} \mathrm{month}^{-1}$ ).

Hemisphere continental snowfall increases in the midlatitudes from $40-60^{\circ} \mathrm{N}$ and decreases poleward of $70^{\circ} \mathrm{N}$ (Fig. 2a). In contrast, the Northern Hemisphere snowfall response in $\triangle \mathrm{MA}$ does not display a systematic latitudinal distribution (Fig. 2b).

The Northern Hemisphere winter snowfall difference between $\triangle$ TOTAL and $\triangle$ MA can be mainly attributed to dynamical adjustments to the seasonal insolation forcing. In $\triangle$ TOTAL, mid-latitude insolation is increased (Fig. 1), enhancing meridional insolation (Fig. 1a) and surface temperature gradients at high latitudes (Fig. 3a). The dynamical response to these changes in radiative heating is an intensification of the meridional circulation (i.e. polar cell) and the associated stationary patterns, including the Aleutian low in the North Pacific (Fig. 3b-c). These adjustments lead to an in- tensification of low-level cyclonic flow (Fig. 3b). Anomalous northwesterly winds intensify the flow of polar air over the northwestern Pacific Ocean, enhancing the local latent heat flux (Fig. 3d). This anomalous moisture is transported by the prevailing winds from the Pacific to North America, and can be identified as a region of enhanced relative humidity stretching across the mid-latitudes (Fig. 3e). An additional source of moisture can also be identified over central North America (Fig. 3d), and arises from enhanced radiative heating over the continent (Fig. 3a). These two moisture sources provide the vapor that contributes to enhanced snowfall over North America (Fig. 3f).

Two additional lines of evidence support our analysis, and confirm the importance of this mechanism for enhancing snowfall. First, in the Southern Hemisphere, where 
(a)
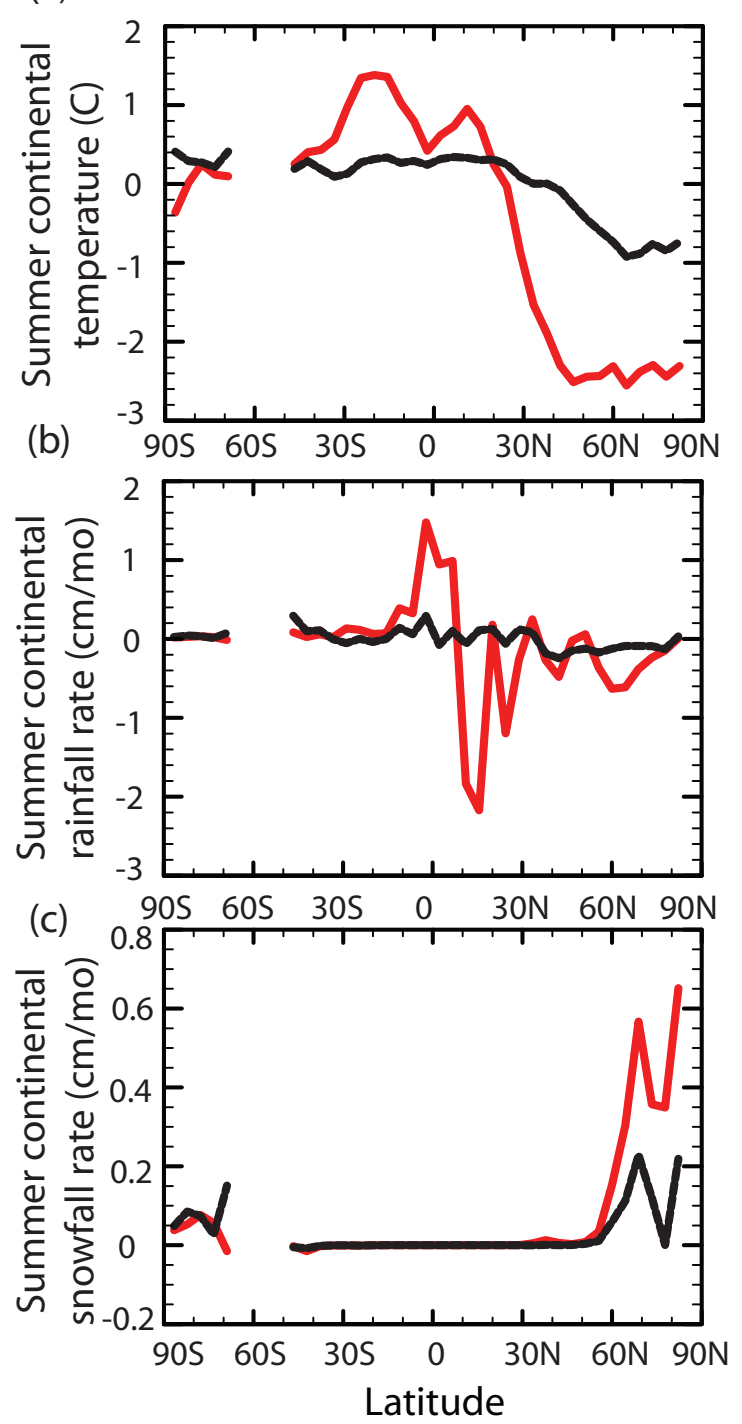

Fig. 4. Differences in zonally-average June-July-August (a) continental surface-air temperature (in degree Celsius), (b) continental rainfall rate (in $\mathrm{cm} \mathrm{month}^{-1}$ ), and (c) continental snowfall rate (in cm month ${ }^{-1}$ ) between experimental sets. Results from $\triangle$ TOTAL (red line) and $\triangle \mathrm{MA}$ (black line) experiments are shown.

stationary patterns are not well pronounced, this dynamic response to seasonal forcing does not occur, and winter snowfall does not change substantially (Fig. 3a, lower panel). Second, in the absence of winter heating in $\triangle \mathrm{MA}$, there is no significant change in Northern Hemisphere circulation, latent heat flux (not shown), or snowfall (Fig. 2b).

\subsection{Summer snowfall response}

In summer, snowfall increases due to both (1) a decrease in air temperature due to a reduction in $\mathrm{NH}$ insolation and (2) an increase in seasonal poleward moisture transport. Summer (June) insolation at $80^{\circ} \mathrm{N}$ decreases by 48 and $25 \mathrm{~W} \mathrm{~m}^{-2}$ in $\triangle$ TOTAL and $\triangle \mathrm{MA}$, leading to decreases in zonal-averaged SATs by 2.5 and $0.5^{\circ} \mathrm{C}$, respectively (Fig. 4a). The larger reduction in SAT in $\triangle$ TOTAL is mainly due to a greater summer sea-ice extent in the "lobl" experiment, which increases local albedo. The reduction in air temperature can partially explain the snowfall responses in $\triangle$ TOTAL and $\triangle \mathrm{MA}$ through (1) the transformation of rainfall to snowfall, and (2) an increase in local atmospheric saturation due to a decrease in saturation vapor pressure following the ClausiusClapeyron relationship. In support of (2), lower troposphere relative humidity increases over most of the northern midand high-latitude regions (Fig. 5a-b). In support of (2), lower troposphere relative humidity increases over most of the northern mid- and high-latitude regions (Fig. 5a-b).

Two lines of evidence indicate, however, that the local temperature decrease only partially explains the summer snowfall increase $\triangle$ TOTAL. First, the increase in (waterequivalent) snowfall is twice the simulated decrease in rainfall (Fig. 4b-c), indicating the existence of additional moisture sources. Second, changes in lower troposphere relative humidity do not directly track changes in temperature. In $\triangle$ TOTAL, for example, the greatest increases in relative humidity occur in the mid-latitudes near $45^{\circ} \mathrm{N}$ (Fig. 5a), while insolation and temperature reductions are greatest at high latitudes (Figs. 1a and 4a).

In addition to absolute insolation, the summer equatorto-pole gradient also changes in $\triangle$ TOTAL and $\triangle$ MA. A reduction in the axial tilt ( $\triangle$ TOTAL) enhances the summer equator-to-pole insolation gradient by up to $55 \mathrm{~W} \mathrm{~m}^{-2}$ (Fig. 1a) leading to a $3^{\circ} \mathrm{C}$ increase in summer meridional temperature gradient (Fig. 4a). In contrast, in $\triangle \mathrm{MA}$, the summer equator-to-pole gradient is enhanced by only $30 \mathrm{~W} \mathrm{~m}^{-2}$ (Fig. 1b) leading to a $0.5^{\circ} \mathrm{C}$ increase in summer meridional temperature gradient (Fig. 4a). As a result of differential heating between low- and high-latitudes, baroclinicity increases in both cases, but the changes are greatest in $\triangle$ TOTAL. In the modern climate, transient eddies increase with baroclinicity and are responsible for transporting heat and moisture between the subtropics and mid-latitude (Trenberth and Stepaniak, 2003). FOAM responds in a similar manner. The high baroclinicity in $\triangle$ TOTAL enhances Northern Hemisphere transient eddy activity leading to a $200 \%$ increase in summer poleward transient eddy vapor transport at $45^{\circ} \mathrm{N}$ and an enhancement in the total vapor transport (Fig. 5e and f). The increase in summer vapor transport provides the moisture for additional boreal continental snowfall, and is reflected in changes in relative humidity (Fig. 5a). As noted above, in $\triangle T O T A L$, the largest increases in relative humidity coincide with regions of enhanced baroclinicity at $\sim 45^{\circ}$ N. Snowfall in the Southern Hemisphere responds in a similar way to an increase in the summer equator-to-pole insolation gradient (Fig. 2a). With a decrease in obliquity, mid-latitude summer baroclinicity, total and transient vapor transport are enhanced (Fig. 5e-h), leading to an increase of $>100 \%$ in the Southern Hemisphere. 
(a) $\triangle$ TOTAL JJA

relative humidity (\%) 180

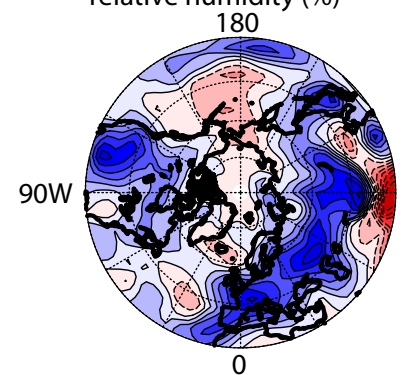

(c) $\triangle$ TOTAL DJF

relative humidity (\%)

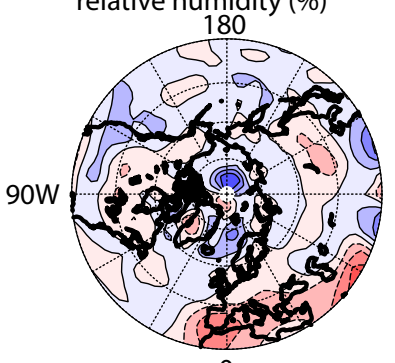

0

$\begin{array}{ccccccccccc}-10 & -8 & -6 & -4 & -2 & 0 & 2 & 4 & 6 & 8 & 10\end{array}$ (b) $\triangle M A J J A$

relative humidity (\%)

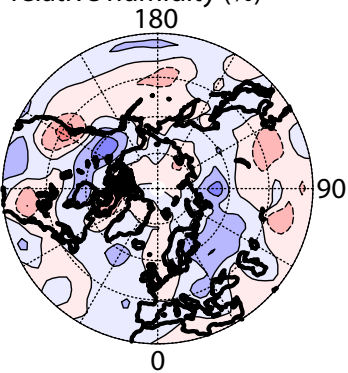

(d) $\triangle \mathrm{MA}$ DJF

relative humidity (\%)

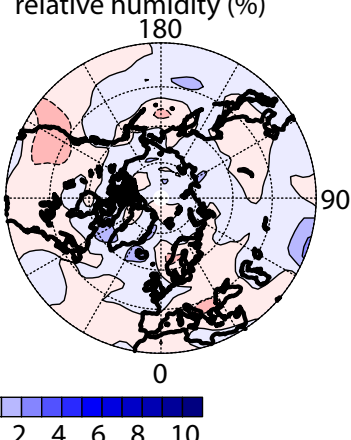

(e) JJA total vapor transport

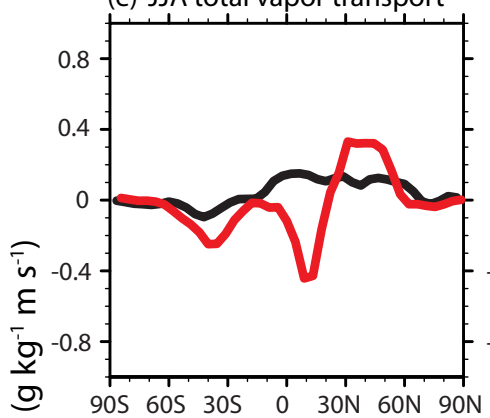

(g) DJF total vapor transport

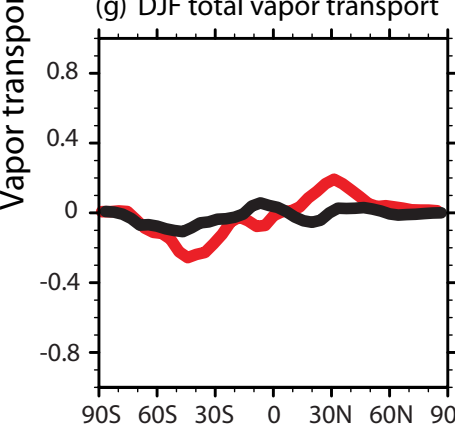

Latitude (f) JJA transient vapor transport

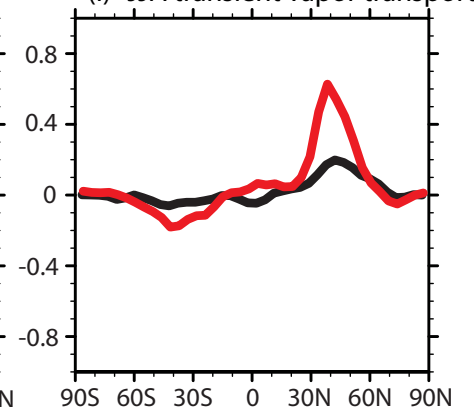

(h) DJF transient vapor transport

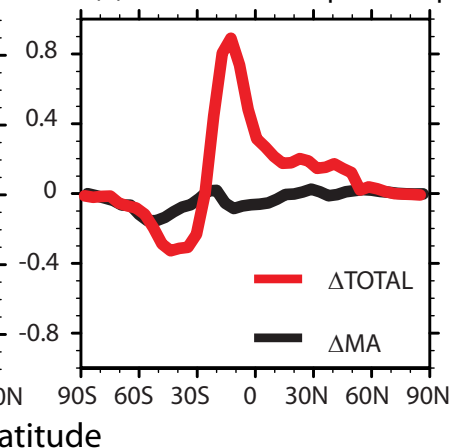

Fig. 5. Response of vapor transports and tropospheric relative humidity to orbital changes. (a-d) Difference maps of lower tropospheric (750 mb) (a-b) June-July-August (c-d) December-January-February relative humidity (\%) for (a, c) $\Delta$ TOTAL and (b, d) $\Delta$ MA. The polar projection maps begin at $30^{\circ} \mathrm{N}$; relative humidity has a contour interval of $1 \%$. Blue represents an increase in relative humidity. Note that the largest increases in relative humidity occur at $\sim 45^{\circ} \mathrm{N}$ in $\triangle$ TOTAL JJA, corresponding to the region of enhanced baroclinicity and vapor transports. Difference in zonal-average (e-f) June-July-August (g-h) December-January-February atmospheric meridional vapor transport $\left(\mathrm{g} \mathrm{kg}^{-1} \mathrm{~m} \mathrm{~s}^{-1}\right)$ by $(\mathrm{e}, \mathrm{g})$ all processes (mean meridional + stationary eddies + transient eddies) and through (f, h) transient eddies between experimental sets. Results from $\triangle$ TOTAL and $\triangle \mathrm{MA}$ experiments are shown in red and black lines, respectively. Positive values represent an increase in northward vapor transport or a reduction in southward vapor transport.

In contrast, in $\triangle \mathrm{MA}$, Northern Hemisphere transient and total vapor transports are only slightly enhanced in summer (Fig. 5e and f). As a consequence, changes in relative humidity mainly track insolation changes, and remain essentially unchanged (small decreases and increases) at $\sim 45^{\circ} \mathrm{N}$ (Fig. 5b).

\section{Implications for the ice volume record}

Changes in obliquity cause variations in both mean annual and seasonal insolation. We have designed numerical experiments to evaluate the relative importance of these insolation changes on continental snowfall. Our model results indicate that the influence of mean annual and seasonal obliquity forcing are approximately equal and account for $44 \%$ and $56 \%$ of global annual continental snowfall, respectively. However, the mechanisms that lead to these snowfall changes differ. The response to mean-annual insolation forcing is mainly through local radiative effects, i.e. atmospheric heating and changes in saturation vapor pressure. In contrast, the response to seasonal insolation forcing through obliquity is amplified in FOAM through winter ocean-to-land vapor transport and summer transient eddy activity (Figs. 3 and 5). Our results highlight the importance of equator-to-pole insolation gradients, and demonstrate that changes in insolation gradients can generate dynamical changes that influence moisture transport and continental snowfall. For perspective, it is worth noting that a decrease in axial tilt ( $\triangle$ TOTAL) led to polar zonal SAT decreases of 6 and $2.5^{\circ} \mathrm{C}$ in $\mathrm{NH}$ winter and summer, respectively. Yet, the snowfall response was $3.5 \times$ greater in the $\mathrm{NH}$ summer, mainly due to enhanced moisture transport through transient eddies.

Our results have important implications for understanding orbital variability in the ice-volume record. Changes in annual and seasonal meridional insolation gradients and associated atmospheric and vapor responses have been hypothesized to cause ice-volume variability (e.g. Khodri et al., 2001; Crucifix and Loutre, 2002; Raymo and Nisancioglu, 2003; Loutre et al., 2004; Vettoretti and Peltier, 2004; Kukla and Gavin, 2004; Risebrobakken et al., 2006). However, this hypothesis has not been explicitly tested in a systematic way before. Our results support the hypotheses that changes in 


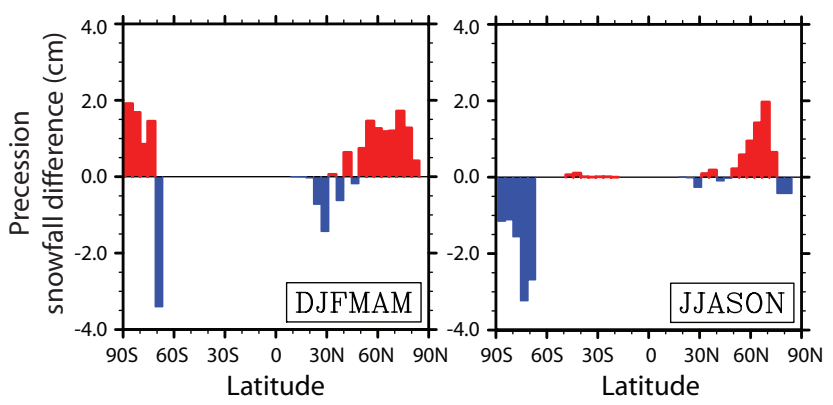

Fig. 6. Zonally-average half-year continental snowfall response to precessional forcing. Snowfall differences are in $\mathrm{cm}$.

equator-to-pole insolation gradients can significantly influence snowfall, and presumably global ice volume. On seasonal timescales, the snowfall response to changes in meridional insolation gradients is amplified through internal climate dynamics, mainly through atmospheric circulation and vapor transport. On mean annual timescales, internal climate dynamics have a smaller effect on continental snowfall.

Although we have shown that orbital forcing by obliquity is amplified leading to greater global ice volume variability, it is not clear whether this amplification is great enough to explain the global ice-volume record, specifically the observation that variability is significantly greater at obliquity timescales than precessional timescales. To directly compare the snowfall response to obliquity and precession, we have completed two additional precessional sensitivity experiments. In these experiments, Northern Hemisphere summer is positioned at aphelion (cold NH summer orbit) and perihelion (warm NH summer orbit), respectively, in an eccentric orbit (eccentricity $=0.056$, which represents the maximum value over the last $3 \mathrm{Ma}$ (Berger et al., 1993)). Precessional oscillation from warm to cold $\mathrm{NH}$ summer orbits increases the continental snowfall in the NH by $14.3 \mathrm{~cm}$ (Fig. 6). Snowfall variations over a processional oscillation result from both thermal and dynamical effects. During the summer half-year, the thermal effect dominates. Snowfall increases (decreases) when $\mathrm{NH}(\mathrm{SH})$ summer insolation and surface temperature decrease (increase) (Fig. 6). The dynamical effect is most apparent during winter when an increase in meridional thermal gradient enhances storm activity, leading to an increase in high-latitude snowfall (Lee, unpublished data). The simulated snowfall response in FOAM to precession is largely similar to climate sensitivities described in Jackson and Broccoli (2003) using an AGCM coupled to a slab-ocean model.

The precessional shift in the orbital position of NH summer leads to a NH continental snowfall response that is $85 \%$ of that calculated due to a change in axial tilt ( $\triangle$ TOTAL). In comparison to a change in obliquity, a change in precession does not influence mean-annual insolation and has only a small influence on summer insolation gradients. However, it has a very large effect (up to $\sim 70 \mathrm{~W} \mathrm{~m}^{-2}$ ) on absolute summer insolation, which contributes to the large snowfall response. This comparison has important implications for the insolation gradient hypothesis. While mean-annual and summer meridional insolation gradient changes associated with a decrease in obliquity may amplify relatively weak insolation forcing, their influence may not be sufficiently large to account for the spectral nature of the ice volume record.

\section{Caveats}

In our experimental design and analysis, we have made several assumptions that warrant discussion. First, throughout our analysis and interpretation, we assume that an increase in snowfall translates into an increase in ice volume. In reality, the ice volume results from a combination of snowfall accumulation and summer ablation. Ablation is often quantified using the positive-degree-day index (PDD), an estimate of melt based on the number of days with near-surface air temperature above the melting point, and a local melt factor. The change in PDD will be much larger in $\triangle$ TOTAL than $\triangle$ MA simply because the change in summer insolation (Fig. 1) and continental surface temperature (Fig. 4a) is much larger. As a result, the inferred ice-volume changes between our $\triangle$ TOTAL and $\triangle \mathrm{MA}$ cases are probably too small. We have not calculated the absolute change in PDD here because the values are sensitive to the mean high-latitude climate, which is strongly influenced by our choice of (modern) trace gas values, and to local melt factors that are not well constrained. In the absence of a dynamic ice-sheet component in our model, it is not possible to calculate the exact ice-volume change that would result from the changes in insolation forcing prescribed here; consequently, our results may be better viewed as continental ice accumulation potential.

In addition, since we simulate the climate response to obliquity insolation changes under present-day boundary conditions, the snowfall response described here does not account for Pleistocene boundary conditions (e.g. $\mathrm{CO}_{2}, \mathrm{CH}_{4}$, and land surface types), which varied between glacial and interglacial times. In a cold climate with low $\mathrm{pCO}_{2}$, it is unclear if the snowfall response to insolation forcing would increase. A decrease in mid-latitude surface temperature would likely cause an increase in summer snowfall and an enhanced moisture transport due to a stronger meridional thermal gradient. However, a decrease in surface temperature might also reduce specific humidity due to a decrease in saturation vapor pressure in a cold climate, leading to a reduction in snowfall.

\section{Summary}

In sum, this contribution systematically identifies climate mechanisms that amplify the climate response to obliquity forcing, and demonstrates that both mean annual and seasonal changes in the meridional distribution of insolation 
play important roles in amplifying this forcing. In particular, seasonal insolation forcing has been shown to influence atmospheric circulation and vapor transport, leading to significant changes in snowfall, and presumably ice volume. Nonetheless, our model results suggest that these climate feedbacks can not fully explain the large spectral power of the 41-kyr cycles relative to the 21-ky cycles in the icevolume record, and the 41-kyr paradox remains just that.

Acknowledgements. This research was supported by National Science Foundation grant ATM-0432503 to C. J. Poulsen, and the University of Michigan Barbour Fellowship and Scott Turner Research Fund to S.-Y. Lee. We gratefully acknowledge constructive comments by M. Loutre, M. Crucifix, W. Ruddiman, and an anonymous reviewer.

Edited by: M.-F. Loutre

\section{References}

Berger, A. and Loutre, M. F.: Insolation Values for the Climate of the Last 10000000 Years, Quat. Sci. Rev., 10, 297-317, 1991.

Berger, A., Loutre, M. F., and Tricot, C.: Insolation and Earths Orbital Periods, J. Geophys. Res.-Atmos., 98, 10 341-10 362, 1993.

Cortijo, E., Lehman, S., Keigwin, L., Chapman, M., Paillard, D., and Labeyrie, L.: Changes in meridional temperature and salinity gradients in the North Atlantic Ocean $\left(30^{\circ}-72^{\circ} \mathrm{N}\right)$ during the last interglacial period, Paleoceanography, 14, 23-33, 1999.

Crucifix, M. and Loutre, M. F.: Transient simulations over the last interglacial period (126-115 kyr BP): feedback and forcing analysis, Clim. Dynam., 19, 417-433, 2002.

Harrison, S. P., Kutzbach, J. E., Liu, Z., Bartlein, P. J., OttoBliesner, B., Muhs, D., Prentice, I. C., and Thompson, R. S.: Mid-Holocene climates of the Americas: a dynamical response to changed seasonality, Clim. Dynam., 20, 663-688, 2003.

Hays, J. D., Imbrie, J., and Shackleton, N. J.: Variations in Earths Orbit - Pacemaker of Ice Ages, Science, 194, 1121-1132, 1976.

Huybers, P.: Early Pleistocene glacial cycles and the integrated summer insolation forcing, Science, 313, 508-511, 2006.

Imbrie, J.: A Theoretical Framework for the Pleistocene Ice Ages, J. Geol. Soc., 142, 417-432, 1985.

Imbrie, J. and Imbrie, J. Z:: Modeling the Climatic Response to Orbital Variations, Science, 207, 943-953, 1980.

Imbrie, J., Mix, A. C., and Martinson, D. G.: Milankovitch Theory Viewed from Devils Hole, Nature, 363, 531-533, 1993.

Jackson, C. S. and Broccoli, A. J.: Orbital forcing of Arctic climate: mechanisms of climate response and implications for continental glaciation, Clim. Dynam., 21, 539-557, 2003.

Jacob, R.: Low frequency variability in a simulated atmosphere ocean system, University of Wis.-Madison, Madison, 159 pp, 1997.

Johnson, R. G.: Major Northern-Hemisphere Deglaciation Caused by a Moisture Deficit 140-Ka, Geology, 19, 686-689, 1991.

Khodri, M., Leclainche, Y., Ramstein, G., Braconnot, P., Marti, O., and Cortijo, E.: Simulating the amplification of orbital forcing by ocean feedbacks in the last glaciation, Nature, 410, 570-574, 2001.
Kiehl, J. T., Hack, J. J., Bonan, G. B., Boville, B. A., Briegleb, B. P., Williamson, D. L., and Rasch, P. J.: Description fo the NCAR Community Climate Model (CCM3) p. 152, 1996.

Kukla, G. and Gavin, J.: Milankovitch climate reinforcements, Global Planet. Change, 40, 27-48, 2004.

Lee, S. Y. and Poulsen, C. J.: Sea ice control of Plio-Pleistocene tropical Pacific climate evolution, Earth Planet. Sci. Lett., 248, 253-262, 2006.

Lisiecki, L. E. and Raymo, M. E.: A Pliocene-Pleistocene stack of 57 globally distributed benthic delta O-18 records, Paleoceanography, 20, PA1003, doi:10.1029/2004PA001071, 2005.

Liu, Z. Y., Kutzbach, J., and Wu, L. X.: Modeling climate shift of El Nino variability in the Holocene, Geophys. Res. Lett., 27, 2265-2268, 2000.

Loutre, M. F., Paillard, D., Vimeux, F., and Cortijo, E.: Does mean annual insolation have the potential to change the climate?, Earth Planet. Sci. Lett., 221, 1-14, 2004.

Milankovitch, M.: Ausbau Und Gegenwartiger Stand Der Astronomischen Theorie Der Erdgeschichtlichen Klimate, Experientia, 4, 413-418, 1948.

Poulsen, C. J., Pierrehumbert, R. T., and Jacob, R. L.: Impact of ocean dynamics on the simulation of the Neoproterozoic "snowball Earth”, Geophys. Res. Lett., 28, 1575-1578, 2001.

Raymo, M. E., Lisiecki, L. E., and Nisancioglu, K. H.: Pliopleistocene ice volume, Antarctic climate, and the global $\delta \mathrm{O}^{18}$ record, Science, 313, 492-495, 2006.

Raymo, M. E. and Nisancioglu, K.: The $41 \mathrm{kyr}$ world: Milankovitch's other unsolved mystery, Paleoceanography, 18(1), 1011, doi:10.1029/2002PA000791, 2003.

Risebrobakken, B., Balbon, E., Dokken, T., Jansen, E., Kissel, C., Labeyrie, L., Richter, T., and Senneset, L.: The penultimate deglaciation: High-resolution paleoceanographic evidence from a north-south transect along the eastern Nordic Seas, Earth Planet. Sci. Lett., 241, 505-516, 2006.

Ruddiman, W. F.: Orbital insolation, ice volume, and greenhouse gases, Quat. Sci. Rev., 22, 1597-1629, 2003.

Ruddiman, W. F.: Ice-driven $\mathrm{CO}_{2}$ feedback on ice volume, Clim. Past, 2, 43-55, 2006, http://www.clim-past.net/2/43/2006/.

Trenberth, K. E. and Stepaniak, D. P.: Seamless poleward atmospheric energy transports and implications for the Hadley circulation, J. Climate, 16, 3706-3722, 2003.

Vettoretti, G. and Peltier, W. R.: Post-Eemian glacial inception. Part II: Elements of a cryospheric moisture pump, J. Climate, 16, 912-927, 2003.

Vettoretti, G. and Peltier, W. R.: Sensitivity of glacial inception to orbital and greenhouse gas climate forcing, Quat. Sci. Rev., 23, 499-519, 2004.

Vimeux, F., Masson, V., Delaygue, G., Jouzel, J., Petit, J. R., and Stievenard, M.: A 420,000 year deuterium excess record from East Antarctica: Information on past changes in the origin of precipitation at Vostok, J. Geophys. Res.-Atmos., 106, $31863-$ $31873,2001$.

Wu, L., Liu, Z., Gallimore, R., Jacob, R., Lee, D., and Zhong, Y.: Pacific decadal variability: The tropical Pacific mode and the North Pacific mode, J. Climate, 16, 1101-1120, 2003. 